JSACE $3 / 12$

Research on the Effect of Water Draining Through Vertical Drainage Systems in the Process of Soil Consolidation

Received 2015/06/08 Accepted after revision 2015/09/29
Research on the Effect of Water Draining Through Vertical Drainage Systems in the Process of Soil Consolidation

\section{Cosmin Fantaziu}

Department Of Transportation Infrastructure and Foundations,"Gheorghe Asachi" Technical University lasi, Faculty of Civil Engineering and Building Services, lasi, 700050, Romania

\section{Răzvan Chirilă}

Department Of Transportation Infrastructure and Foundations,"Gheorghe Asachi" Technical University lasi, Faculty of Civil Engineering and Building Services, lasi, 700050, Romania

Corresponding author: fantaziucosmin@yahoo.com

$\Gamma$ Crossef $h t t p: / / d x . d o i . o r g / 10.5755 /$ j01.sace.12.3.12655

A saturated soil subjected to a growing total effort will reduce gradually the volume up to excess pore water pressure dissipation, interfering primary consolidation. This process can take a long time and when all excess pressure is dissipated, the soil is considered consolidated.

In low permeability soils, from external loading, results in an increase of the normal effort at higher values than the earth preconsolidation pressure, thus having neutral increased pressure followed by a consolidation process where water is expelled from the pores of the soil. The decrease in porosity (soil volume), so produced, is accompanied by a gradual increase of effective pressure and a corresponding decrease in excess pore water pressure. The consolidation process continues until the excess pore water pressure dissipates only complete and upload translates into effective stress. Duration of the process depends on the consolidation characteristics of the soil and drainage ways (with how much drainage paths are longer, the longer is the process of consolidation). The purpose of installing vertical drains is to shorten the drainage ways and time needed to dissipate the neutral pressure. The time to dissipate the excess water pressure in the pores (time consolidation) is so short as the inter-distance between the drains is less.

KEYWORDS: consolidation, drainage, pore pressure, settlement.

In order to accelerate the process of settlement (consolidation) and reduce pore water pressure, it is necessary to shorten the length of road drainage through the soil pore water. This can be achieved by placing vertical drains in the ground at calculated distance. The presence of this drainage system enables the pore water overpressure to be eliminated by the nearest horizontal drainage system and free-flowing. By using vertical drains the needed time consolidation process, can usually be reduced from decades to one year or less.

Execution a network of vertical drains is a means to accelerate the settlements produced in the process of long-term consolidation. Another objective of the execution of those works is to improve the conditions for stability of the earth by increasing its shear strength. In areas of high seismic activity, vertical drainage networks can be used to reduce the phenomena of liquefaction. 
Examples of areas where this method is usually used:

_ Road and railway embankments;

_ Building and strengthening dykes;

_ Earthworks made for the construction of the residential, industrial plants, terminals, etc.;

- Preload fillings;

_ Coastal and marine construction;

_ Land reclamation, ports and airports.

The specific functional requirements to each project, underlying geotechnical design vertical drainage. Steps to approach a vertical drainage project execution, include achieving a working platform, execution a draining mattresses, drawing drainage network model and the installation of drains, followed by loading and monitoring, Fig. 1.

Installing vertical drains may adversely affect the original properties of the earth (eg, decrease shear strength and coefficient of consolidation), so analysis of site conditions reported to drainage method must be very rigorous.

Due to the excess pressure of the water from the pores created by the load, the ground water is set in motion in the horizontal direction and then is discharged through the drains. An amount of water, generally low, is drained in a vertical direction as a result of one-dimensional consolidation.

For the research was used Plaxis 2D, which is an advanced calculation using the finite element method for analyzing two-dimensional problems of deformation and stability in geotechnical engineering. Plaxis 2D program involves three subprograms called data entry, data calculation program and display the results. Performs analysis in plane or axi-symmetry version with 6 or 15 nodes triangular element.

In order to describe a ground deformations resulting from changes in the current effort, a mathematical model was assigned to the earth. It governs the relationship stress-strain and is called material model. In Plaxis 2D are available a number of materials models. However, this paper will address the Mohr-Coulomb model only.

Consolidation analysis is used in Plaxis 2D when it is necessary to evaluate the dissipation of excess pore water pressure of saturated clay function of time. Here, the important parameter isn't the type of material drainage but rather permeability parameter specified. Is it possible to consolidate with and without additional surcharge.

A saturated soil subject to a total effort/strain will reduce gradually the volume up to dissipate excess pore water pressure, interfering primary consolidation. This process can take a long time and when all excess pressure is dissipated, the land is considered consolidated.

Analysis of the effect of water drainage through vertical drains was achieved by taking into account three assumptions: no drains, with drains placed at $2.0 \mathrm{~m}$ between them and sand drains, placed at $2.0 \mathrm{~m}$ inter-distance between them. The distance between the two types of drains, was choosen to show the efficiency from the point of view of performance and economic solution. This distance can be modified depending on the needs of drainage, but the $2.0 \mathrm{~m}$ between drains is the most common distance applied. The distance between the drains are kept smaller than the thickness of surcharge to reduce radial length of the drainage length.
Fig. 1

Representing sand drainage system 


\begin{tabular}{|c|c|c|c|c|c|c|c|c|c|c|c|}
\hline \multirow{8}{*}{$\begin{array}{c}\text { Table } 1 \\
\text { Stratification } \\
\text { characteristics }\end{array}$} & ID & Name & Type & $\begin{array}{c}Y_{\text {unsat }} \\
{\left[\mathrm{kN} / \mathrm{m}^{3}\right]}\end{array}$ & $\begin{array}{c}Y_{\text {sat }} \\
{\left[\mathrm{kN} / \mathrm{m}^{3}\right]}\end{array}$ & $\begin{array}{c}k_{x} \\
{[m / d a y]}\end{array}$ & $\begin{array}{c}k_{y} \\
\text { [m/day] }\end{array}$ & {$[-]$} & $\begin{array}{c}E_{r e f} \\
{\left[k N / m^{2}\right]}\end{array}$ & $\begin{array}{c}\mathrm{c}_{\mathrm{ref}} \\
{\left[\mathrm{kN} / \mathrm{m}^{2}\right]}\end{array}$ & $\begin{array}{c}\varphi \\
{\left[{ }^{\circ}\right]}\end{array}$ \\
\hline & 1 & Dusty clay & Undrained & 16,0 & 19,9 & 2,6E-03 & 1,3E-03 & 0,35 & 30000 & 20 & 5 \\
\hline & 2 & $\begin{array}{l}\text { Compressible } \\
\text { clay }\end{array}$ & Undrained & 14,8 & 19,1 & $5,2 \mathrm{E}-04$ & 2,6E-06 & 0,35 & 10000 & 10 & 5 \\
\hline & 3 & $\begin{array}{l}\text { Very } \\
\text { compressible } \\
\text { soft plastic clay }\end{array}$ & Undrained & 15,0 & 19,0 & 1,1E-03 & 5,5E-04 & 0,35 & 3221 & 8 & 4 \\
\hline & 4 & Dusty clay & Undrained & 15,2 & 18,4 & 2,0E-04 & $1,0 \mathrm{E}-04$ & 0,35 & 18000 & 32 & 6 \\
\hline & 5 & $\begin{array}{l}\text { Incompressible } \\
\text { clay }\end{array}$ & Undrained & 18,0 & 20,0 & 1,0E-04 & 1,0E-04 & 0,35 & 45000 & 25 & 9 \\
\hline & 6 & Drainage layer & Drained & 18,0 & 20,0 & 8,6430 & 4,3215 & 0,30 & 30000 & 1 & 20 \\
\hline & 7 & $\begin{array}{l}\text { Filling } \\
\text { embankment }\end{array}$ & Drained & 18,0 & 19,0 & 8,6430 & 4,3215 & 0,30 & 30000 & 10 & 25 \\
\hline
\end{tabular}

Based on the results obtained in the three hypotheses considered, they were analyzed as graphics, consolidation process characteristic parameters such as displacements, times of consolidation and pore water pressures.

Modeling was performed on a layered soil profile, with high compressibility clays and incompressible. It was executed a precharge step, serving to highlight the neutral pressure dissipating way and settlements-time curve shape. In Table 1 it is presented the type stratifications and geotechnical characteristics, with an increased interest on very compressible soft plastic clay layer.

Considering the chosen stratification, the greatest interest in analyzing the consolidation process it is represented by the very compressible clay layer. Hydrogeological conditions generated by the model (groundwater level at $-2.0 \mathrm{~m}$ depth) are modified by arranging vertical drains, lines along which the neutral pressure reduced to zero. At the ground surface has represented a drainage layer (mattress), with thickness of $0.5 \mathrm{~m}$, which will ensure water drainage. Above this draining layer it is made the embankment of ground filler (preloading equivalent). Execution of fill in embankment, will realize in two stages, each stage of each $1.5 \mathrm{~m}$ height.

Contour conditions (the model limits), involves locking the horizontal displacements, while in vertical direction the displacements are free. Drainage is prevented from lower limit of the model and

Fig. 2

The layout analyzed stratifications

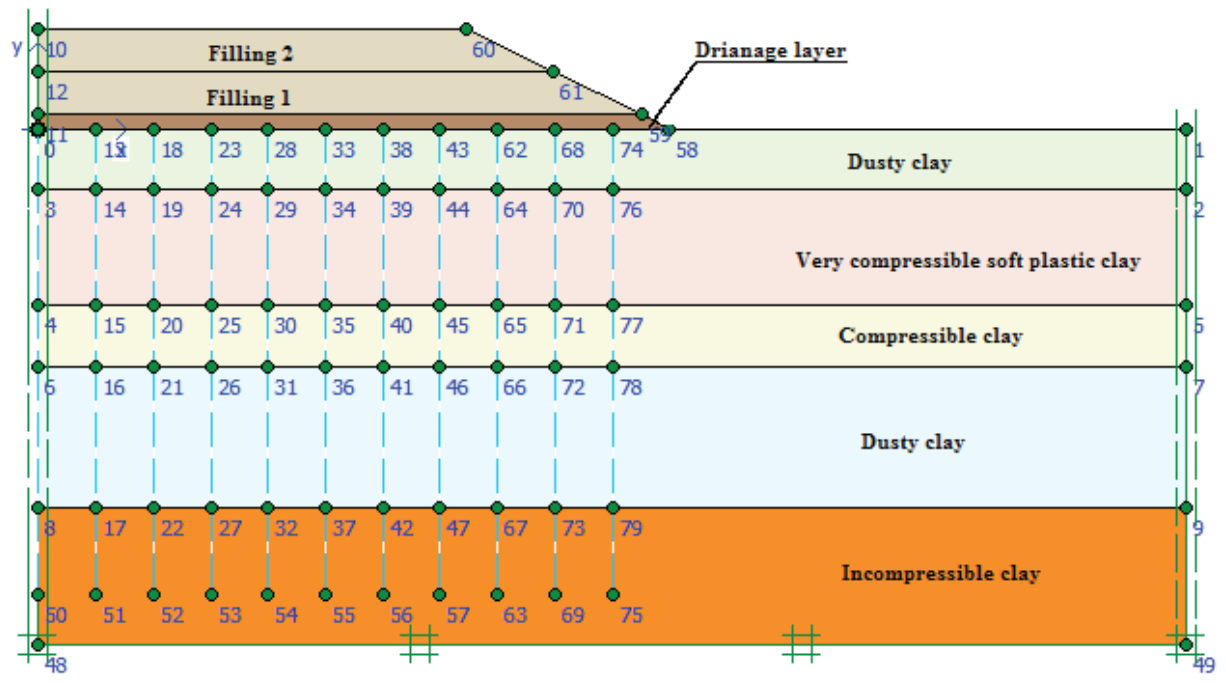


to the side, open only to the top by drainage mattress. Finite element mesh network with integration type 15 knots in 12 Gauss points.

The model is conducted in three-phase construction, different, to the hypothesis that involves carrying out the drains and the sand columns, in the following order:

- The first stage involves achieving vertical drains or sand columns, and draining sand mattress;

- The second stage involves the execution of the first stage preload by making the first backfill layer of filler;

The third step involves carrying out the second step of preload, by executing the second filling layer.

There is a last phase of computing, which aims to verify the stability of the model according to the conditions and simulation obtained. Referring to Fig. 3 , the stability of the model is secured by a safety factor of 1.62, for vertical drainages, and 1.71, for sand columns.
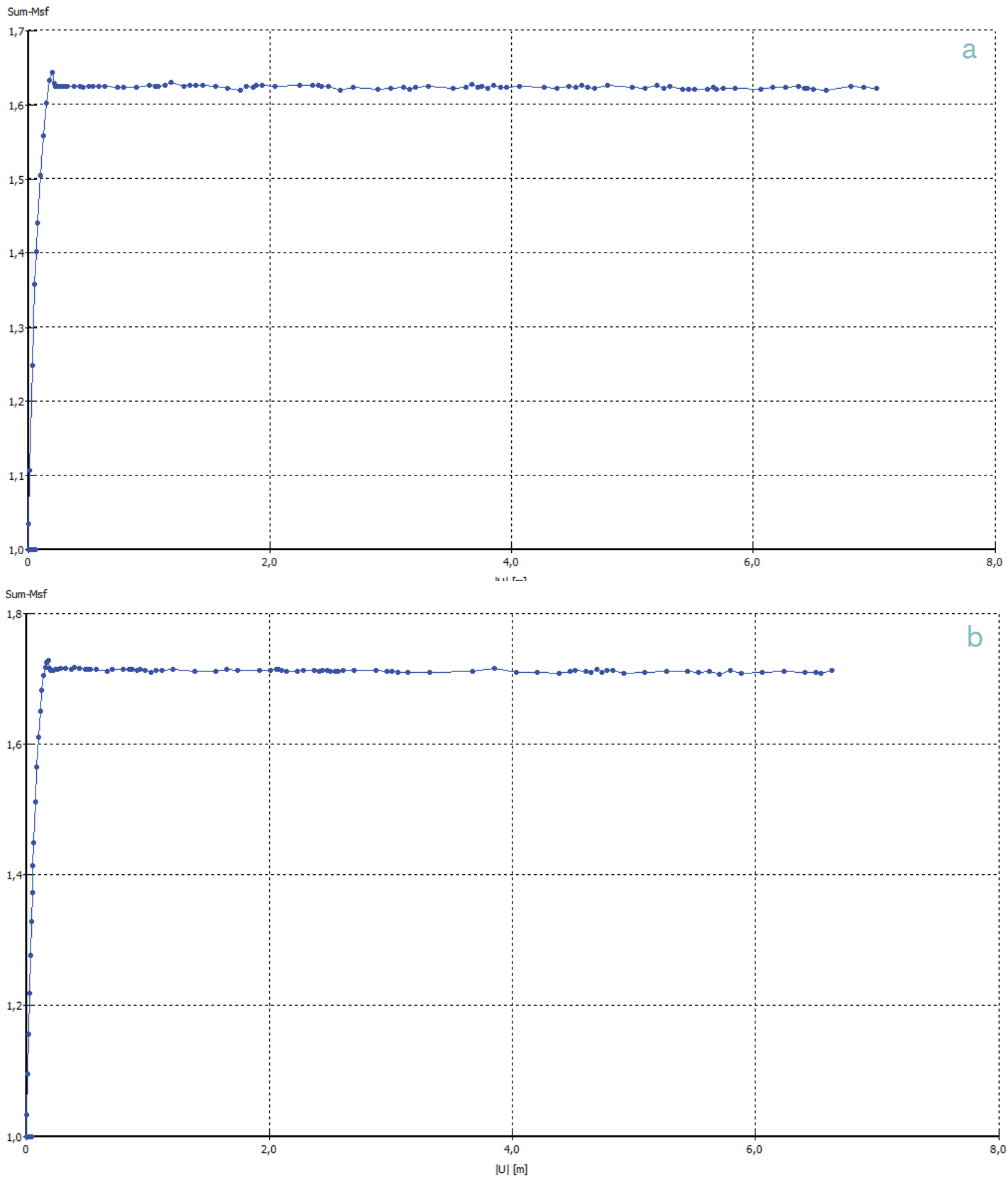

Fig. 3

Reporting safety factor to the evolution of displacements in 2 cases: a) vertical drainages;

b) sand drainages 
Results

Fig. 4

The total displacement after consolidation (finite element mesh), for 2 cases

Fig. 5

The vertical displacement (settlement), representing the contour lines, for 2 cases

Fig. 6

The average effective effort, code color representation, for 2 cases
After running calculation, were obtained the results shown in the following. Figure 4 highlights deformed mesh network, the scale deformations is 50:1. The maximum total displacement obtained at the end of the consolidation process, it is $4.8 \mathrm{~cm}$ for vertical drainages, and $5.2 \mathrm{~cm}$, for sand columns, otherwise it represents, as shown in Figure 5, the maximum settlement to share common $\pm 0.00 \mathrm{~m}$ (natural ground surface).

The average effective effort is illustrated in Figure 6, in the color code. It notes the increase with its depth, but also the inside of the model. The average effective effort is one of compression and has a maximum value of $157.53 \mathrm{kN} / \mathrm{m}^{2}$ for vertical drainages, and $166.49 \mathrm{kN} / \mathrm{m}^{2}$, for sand columns, but the value is found after the $-15.00 \mathrm{~m}$ depth.

Figure 7 is represented by the main directions, the total effort, with maximum value of $382.82 \mathrm{kN} / \mathrm{m}^{2}$ for vertical drains, and $401.53 \mathrm{kN} / \mathrm{m}^{2}$, for sand drains.

The excess pressure of pore water (neutral pressure) is highlighted in Figures 8 during the consolidation process (last step of the pre-load) and 9 at the end of consolidation process. In Figure 8 , there is an immediate impact by reducing drains along their neutral pressure. Figure 9 illustrates the end of the consolidation process, a neutral pressure concentration in the area outside the influence of drains, but the value is very low, about $0.72 \mathrm{kPa}$ for vertical drainages, and $0.69 \mathrm{kPa}$ for sand drains.
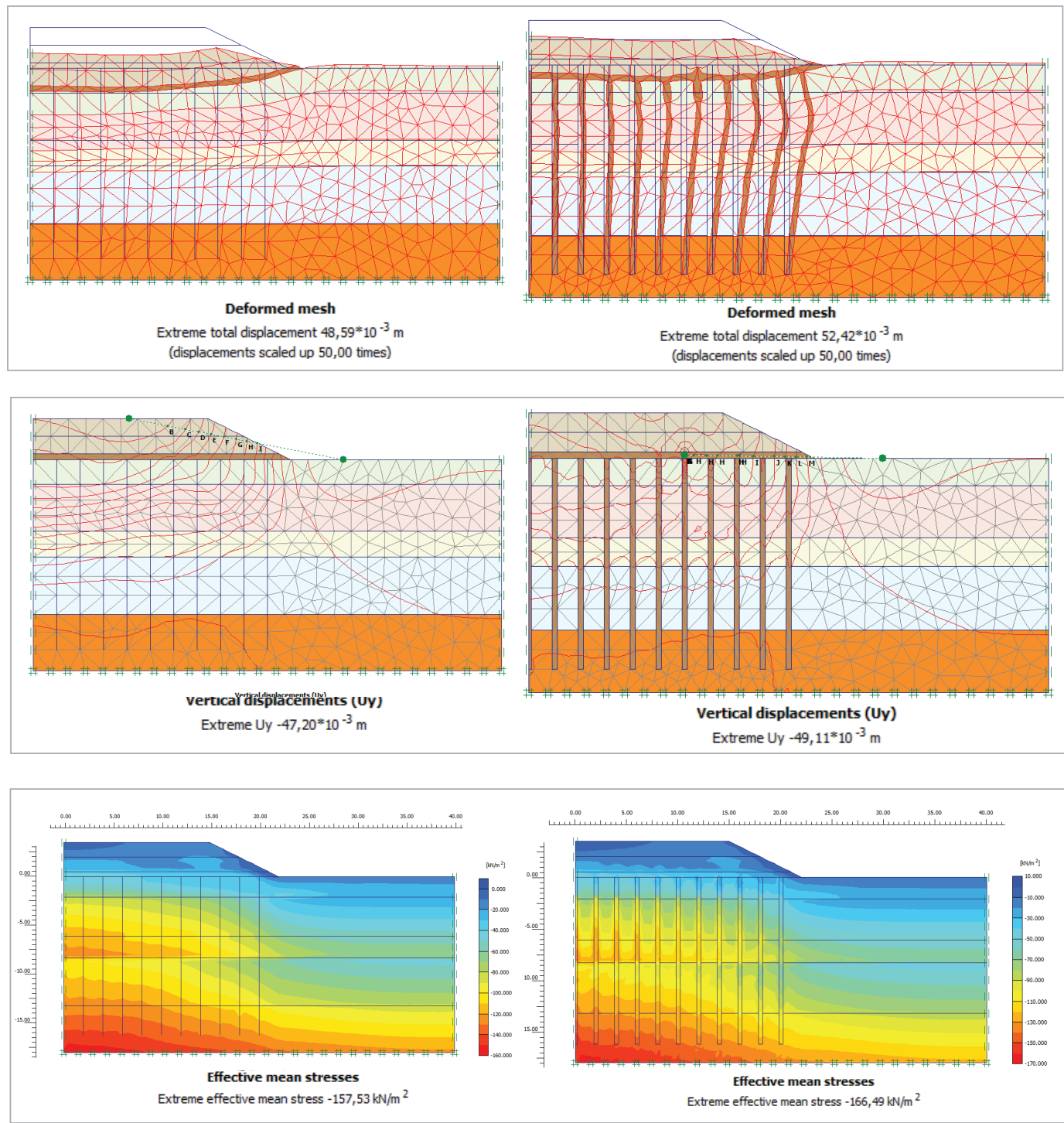


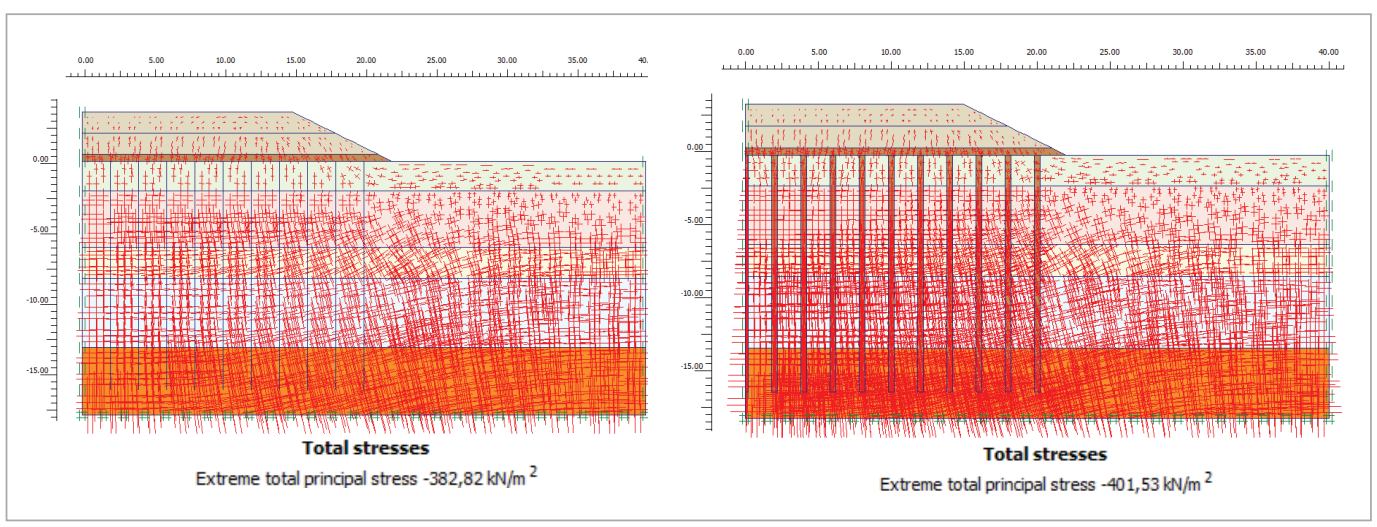

Fig. 7

The total effort, represented by the main directions,

for 2 cases

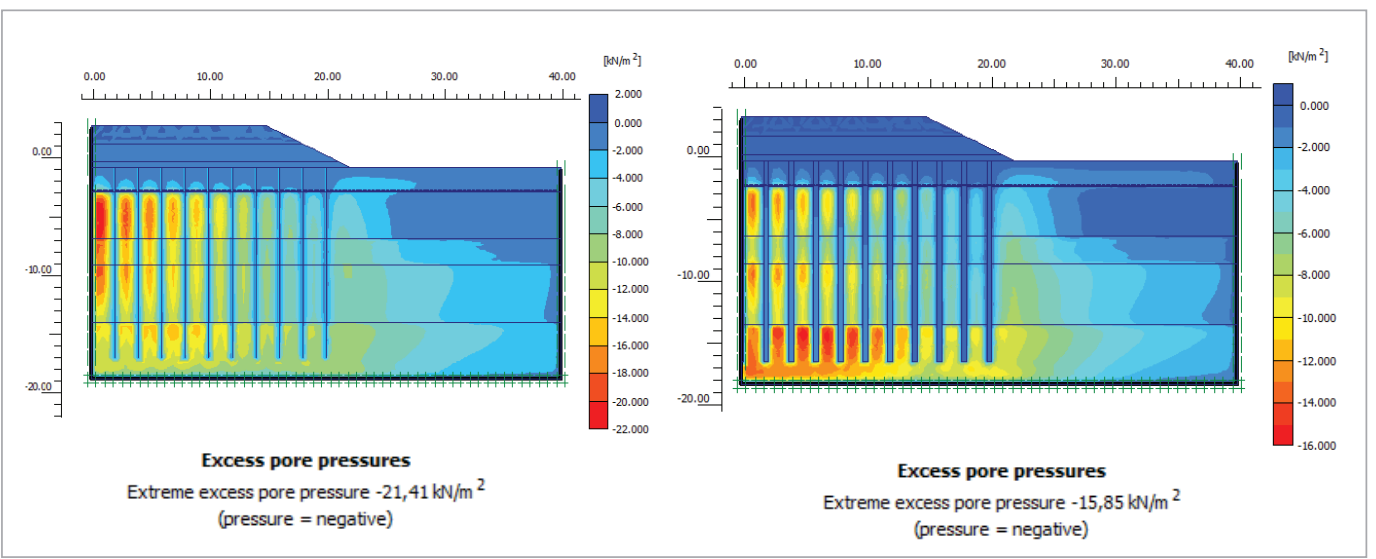

Fig. 8

Neutral pressure during the consolidation process, color code representation, for 2 cases

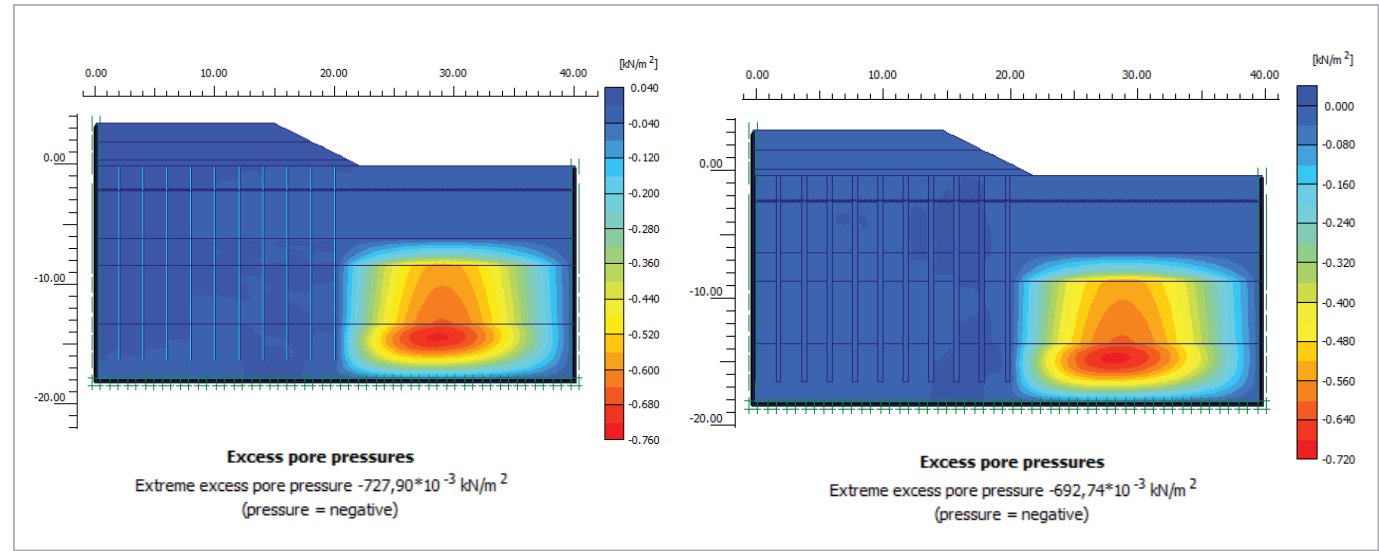

Based on the results, comparative analysis was made in the calculation assumptions, the main parameters consolidation process characteristics such as displacements, consolidation time, effective and total efforts, pore water pressures.

Improving by the drainage is observed since the analysis of the evolution settlements reported on time, Figure 10 maximum land surface settlement in the cases considered, varies between 2 and $4 \mathrm{~cm}$. Alura-time settlement curves are following stages of construction, with a considerable increase in the precharge phase followed by slow levels, representative for consolidation phases. The influence is shown by drainage time consumption of settlements, which is 1733 days under free drainage, 616 days when using sand drains and 622 days for vertical drains.

\section{Fig. 9}

Neutral pressure at the end of consolidation process, color code representation, for 2 cases 
Fig. 10

The settlement recorded in the share $\pm 0,00 \mathrm{~m}$

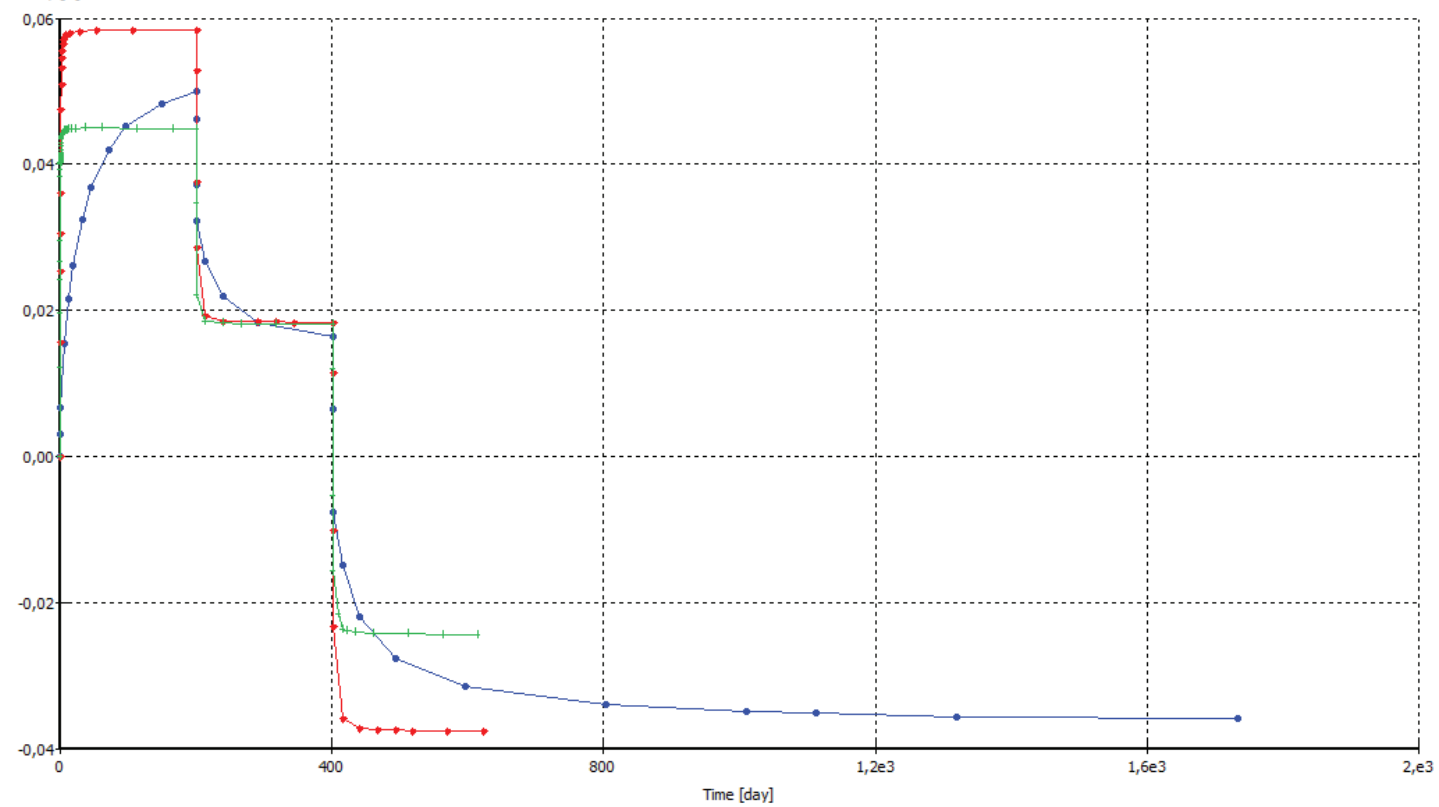

The same phenomenon can be observed in depth at -2.4 m (Figure 11) and -8.3 m (Figure 12). As regards the time evolution of the lateral displacement at the ground surface, Fig. 13 shows a more rapid increase in lateral movements in drained conditions, but it is dictated by rate of consolidation in each case separately. At the end of the consolidation, the maximum lateral displacements in the three hypotheses considered and measured in section A-A (Fig. 14) reaches following values:

- without drainage: $23 \mathrm{~mm}$;

- with vertical drains $2 \mathrm{~m}: 16 \mathrm{~mm}$;

- with sand drains: $10 \mathrm{~mm}$.

Fig. 11

Settlement at $-2.4 m$ depth

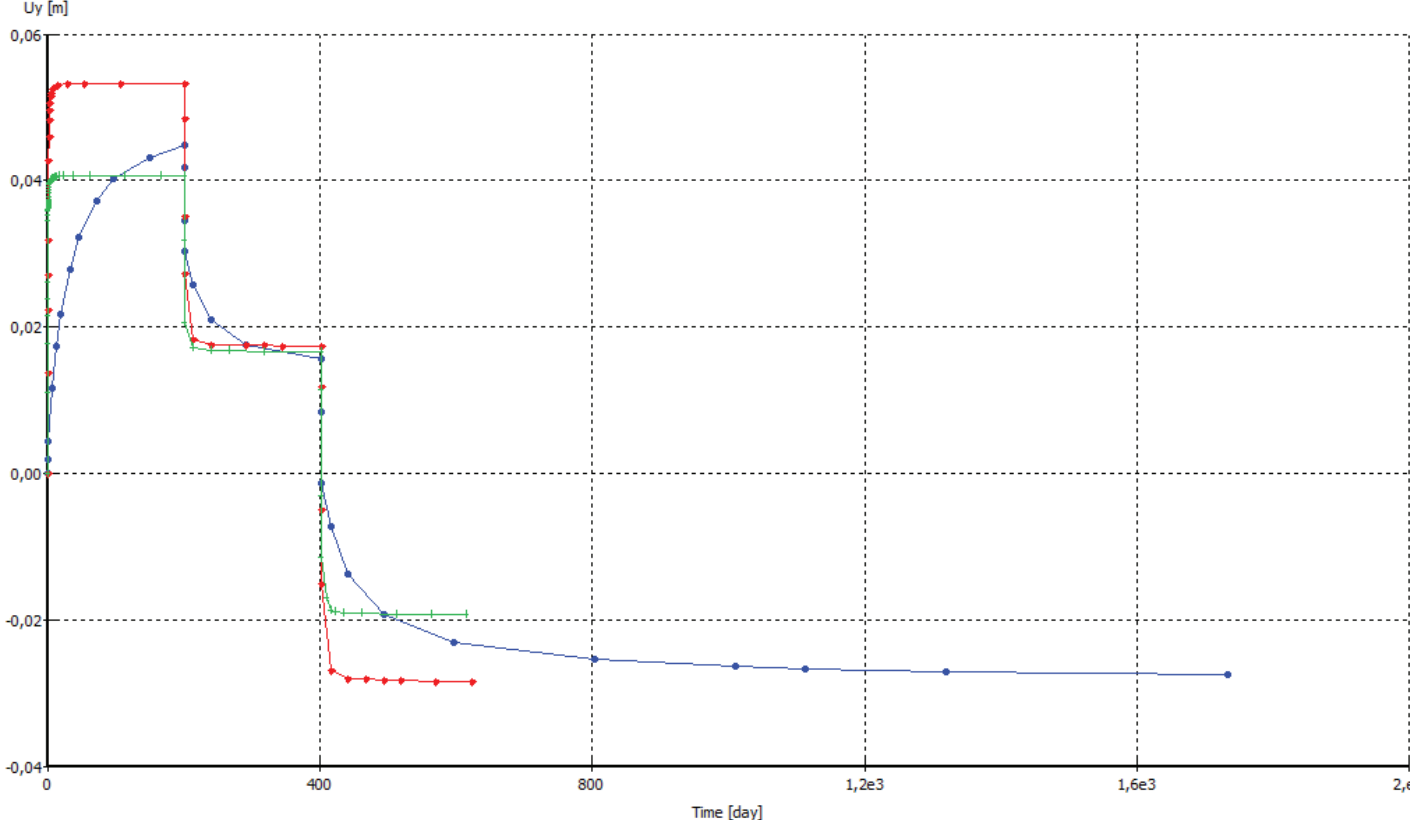


It can be concluded therefore that the consolidation process of compressible clays, drainage it has influence in reducing vertical and lateral movements.

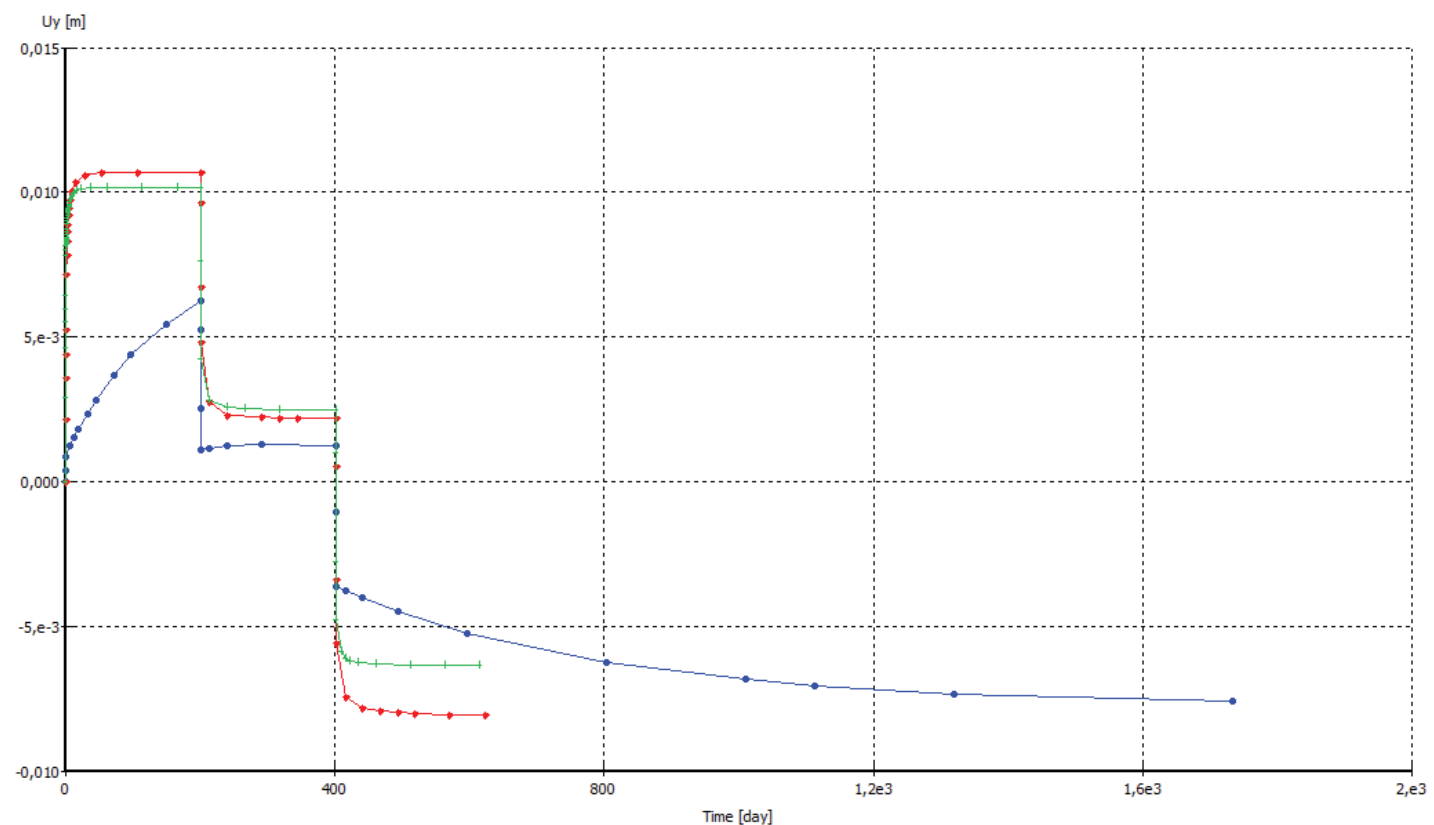

Fig. 12

Settlement at $-8.3 \mathrm{~m}$ depth

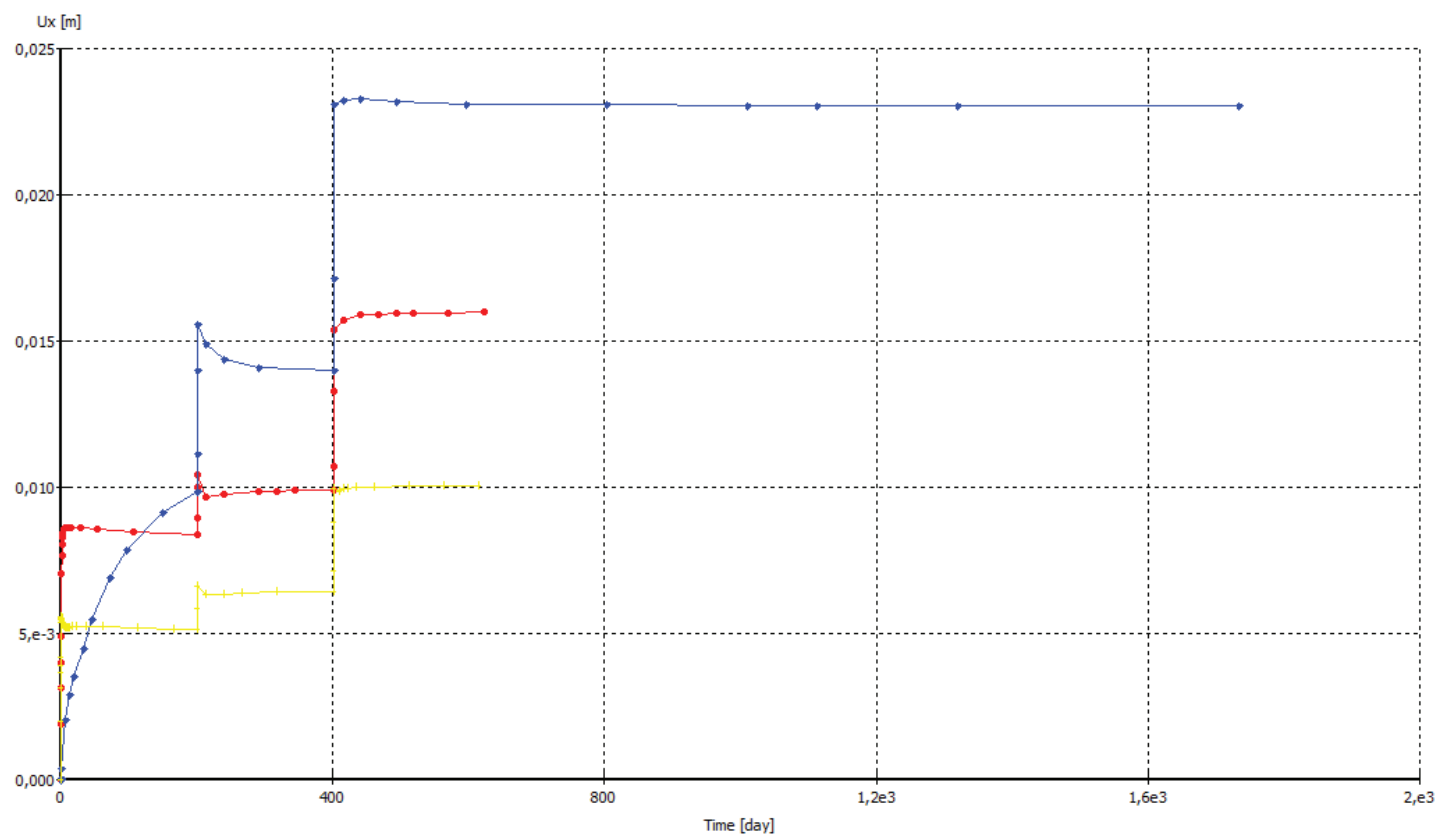

Fig. 13

The lateral displacement recorded at the share $\pm 0,00 \mathrm{~m}$, section $\mathrm{A}-\mathrm{A}$ 
Fig. 14

Horizontal displacements distribution with the depth: a - Section A-A*; $b$ - Section B-B*
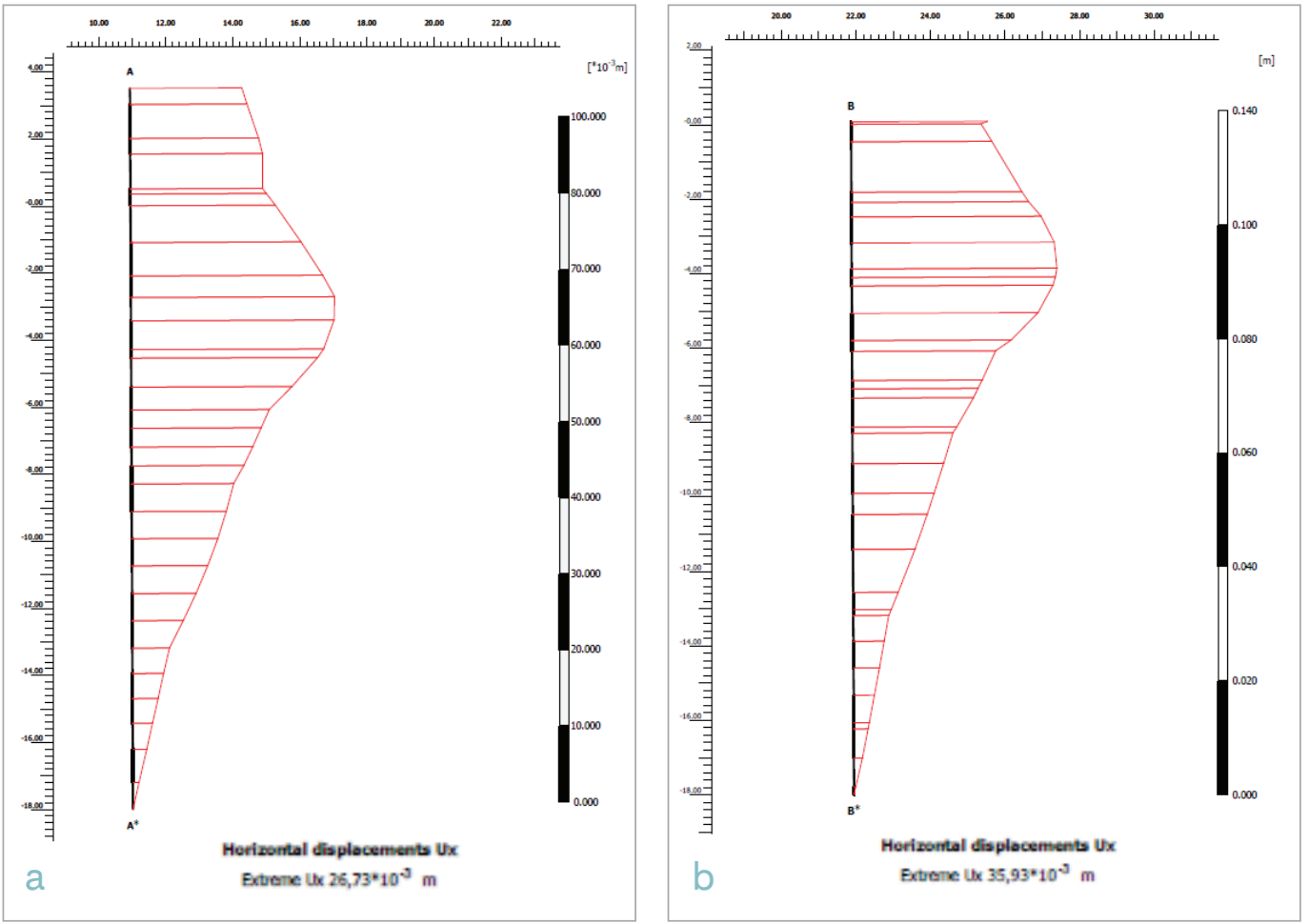

Fig. 15

Cross sections $A-A^{*}$ and $B-B^{*}$ through terrain profile

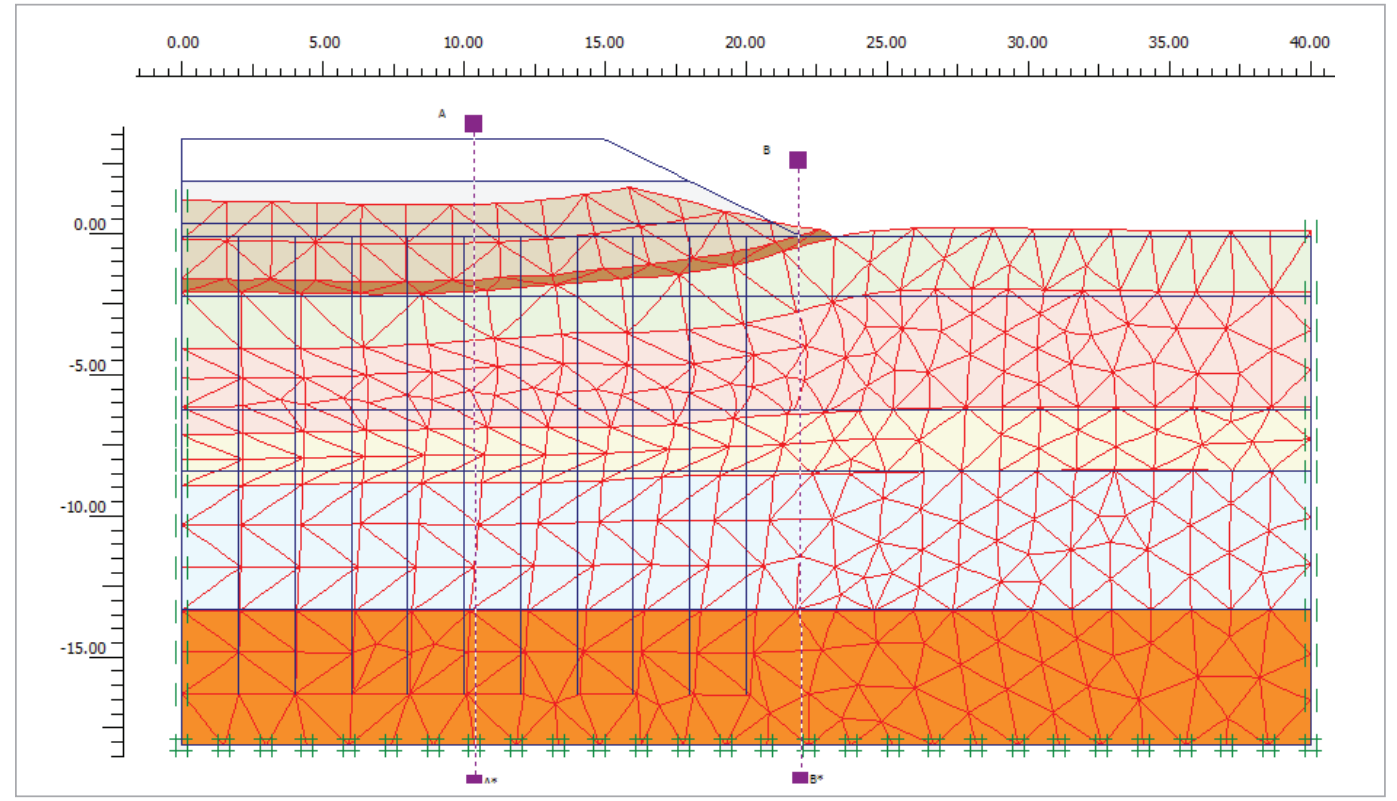

It may outline the following conclusions:

Conclusions

Vertical drainage has an important influence on the time of consumption of settlements. If in the case without the drains, this time is estimated at 1733 days, with the drains arranged at $2 \mathrm{~m}$ between axles or sand drains, amortization time is substantially reduced to a minimum of 622 days ( 1.7 years) if drains spaced at $2 \mathrm{~m}$ inter distance or 616 days ( 1,68 years) with sand drains. 
When using vertical drains, lateral displacements are decreased by over 35\%, compared to normal mode without drainage;

- Correlation between normal and shear stress in effective values, highlights that the same amount of loading, in drainage conditions, the shear stress values are lower than in the case without drains;

- On excess pressure on the pore water, drainage effects from normal consolidation level at loading aplication, are indicated by a lower value of neutral pressure and by speeding up dissipate velocity of it;

In the consolidation process, characteristic parameters (settlement, neutral pressure, lateral displacement), varies depending on each other. The acceleration of consolidation process, drainage occurs on the time factor, through rate of neutral dissipation pressure.

Abdulhafiz Omar S. Alshenawy Determination of the coefficient of consolidation using different methods and study the effect of applied pressure for different types of soils, Safar 1428 H, 2007

Crawford C. B. Interpretation of the consolidation test, Journal of the Soil Mechanics and Foundations Division, Vol. 90, p. 87-102, 1964

Dinesh S. V. Consolidation of soils, Institute of Technology Tumkur, 2003

Indraratna B., Chu J. Ground Improvement - Case histories, Ed. Elsevier, Oxford, 2005

Indraratna B., Rujikiatkamjorn C., Sathananthan I. Radial consolidation of clay using compressibility indices and varying horizontal permeability, Canadian Geotechnical Journal, 2005

Karstunen M. Influence of features of natural soft clay on behaviour of embankment, Journal of Central South University of Technology 18 (5), 1667-1676, 2011 Lancellotta R. Geotechnical engineering, Taylor\&Francis, Abingdon, Oxon, 2009
Maftei G. Îmbunătățirea terenului de fundare sisteme de drenaj [Improvement of foundation soil drainage systems], Teză de doctorat, Universitatea Tehnică Gh. Asachi, laşi, 2014

Mats Kahlström Plaxis 2D comparison of Mohr-Coulomb and soft soil material models, Luleå University of Technology, Sweden, 2013

Stanciu A., Lungu I. Fundații - Fizica şi mecanica pământurilor [Physics and mechanics of soils], Editura Tehnică Bucureşti, 2006

Xiaodi S., Xiaoxian S., Wenhui D.: Element analysys of consolidation of soil under surcharge and vacuum preloading, 2nd International Conference on Electronic \& Mechanical Engineering and Information Technology (EMEIT - 2012)

Wong Y.K., Joseph Comparison of drainage line elements in PLAXIS 2D and 3D applied in consolidating marine clay deposits, Soft Soil Engineering International Conference, Sarawak, Malaysia, 2013

\section{COSMIN FANTAZIU}

\section{PhD student}

"Gheorghe Asachi" Technical University lasi, Department Of Transportation Infrastructure and Foundations

\section{Main research area}

Geotechnical engineering and soil consolidation

\section{Address}

43 D. Mangeron, 700050 iasi, Romania

Tel. +074 3890336

E-mail: fantaziucosmin@yahoo.com

\section{RĂZVAN CHIRILĂ}

PhD student

"Gheorghe Asachi" Technical University lasi, Department Of Transportation Infrastructure and Foundations

\section{Main research area}

Geotechnical engineering and soil consolidation

\section{Address}

43 D. Mangeron, 700050 iasi, Romania

Tel. +0742085262

E-mail:razvan_fcs@yahoo.com

\section{References}

\section{About the authors}

